\title{
Use of Chemoradiotherapy as a Treatment Option for Patients with Limited-Stage Primary Small Cell Carcinoma of the Esophagus
}

This article was published in the following Dove Press journal: Cancer Management and Research

\author{
Kaikai Zhao' \\ Zhaogin Huang ${ }^{2}$ \\ Youjiao $\mathrm{Si}^{3}$ \\ Liangchao Sun (iD) ${ }^{4}$ \\ Jinming $\mathrm{Yu}^{4}$ \\ Xiangjiao Meng $\mathbb{( D}^{4}$ \\ 'Department of Radiation Oncology, \\ Yantai Affiliated Hospital of Binzhou \\ Medical University, Yantai, People's \\ Republic of China; ${ }^{2}$ Department of \\ Radiology, Shandong Provincial Hospital \\ Affiliated to Shandong First Medical \\ University, Jinan, Shandong, People's \\ Republic of China; ${ }^{3}$ Department of \\ Radiology, Yantai Affiliated Hospital of \\ Binzhou Medical University, Yantai, \\ People's Republic of China; ${ }^{4}$ Department \\ of Radiation Oncology, Shandong Cancer \\ Hospital and Institute, Shandong First \\ Medical University and Shandong \\ Academy of Medical Sciences, Jinan, \\ People's Republic of China
}

Purpose: Currently, there are no standard treatments for primary small cell carcinoma of the esophagus (PSCCE), particularly in cases of limited-stage disease. This retrospective study aimed to assess the treatment strategies and the relevant prognostic factors of limited-stage PSCCE (LS-PSCCE).

Patients and Methods: We retrospectively evaluated 129 patients with LS-PSCCE between June 2009 and December 2018. The $\chi 2$ test was performed to examine the frequencies between different groups. The Kaplan-Meier and log-rank methods were used to estimate and compare survival rates. Univariate and multivariate analyses were performed to determine the prognostic factors for overall survival (OS).

Results: Through a median follow-up of 23 months, the median OS of all patients was 25.0 months and the median recurrence-free survival (RFS) was 15.0 months. Univariate and multivariate analyses showed that alcohol abuse $(p=0.046)$ and TNM stage $(p<0.001)$ were independent prognostic factors. There was no significant difference in OS and RFS rates between the patients treated with chemoradiotherapy (CRT) and those treated with surgery and chemotherapy with or without radiotherapy $(\mathrm{S}+\mathrm{CT} \pm \mathrm{RT})(p>0.05)$. Patients who received concurrent CRT had better OS and RFS than those who received sequential CRT $(p<0.05)$. Postoperative adjuvant RT for high-risk patients can further improve the local control rate but has no significant effect on OS.

Conclusion: LS-PSCCE patients treated with CRT had similar OS and RFS compared to those treated with $\mathrm{S}+\mathrm{CT} \pm \mathrm{RT}$. This study shows that concurrent CRT confers a survival advantage for patients with LS-PSCCE compared to those with sequential CRT.

Keywords: primary small cell carcinoma of the esophagus, limited-stage, chemoradiotherapy, surgery

\section{Introduction}

Primary small cell carcinoma of the esophagus (PSCCE) is a rare and highly aggressive malignancy characterized by early metastasis and poor prognosis. ${ }^{1}$ PSCCE has an incidence of less than $2.8 \% ;^{1-3}$ therefore, large-scale treatment analyses are lacking and no prospective randomized studies have been conducted thus far.

To date, the main treatments for LS-PSCCE have included surgery, radiotherapy (RT), and chemotherapy (CT) and have been based on small retrospective studies. The role of surgery in patients with LS-PSCCE is controversial. ${ }^{4}$ It has been reported that most patients with LS-PSCCE received surgical treatment, and the
Correspondence: Xiangiiao Meng Department of Radiation Oncology, Shandong Cancer Hospital and Institute, Shandong First Medical University and Shandong Academy of Medical Sciences, Jinan 250 I 17, People's Republic of China Tel +86 I3793I50996

Email mengxiangjiao@I26.com
Cancer Management and Research 2021:13 613-623

DovePres: in $\square$ 
results indicated that radical esophagectomy should be considered as the primary treatment for stage I or IIA PSCCE. $^{5}$ Similar results were obtained by Wong et al. ${ }^{6}$ However, surgery alone often results in rapid systemic recurrence. $^{7,8}$ Several studies have shown that chemoradiotherapy (CRT) could also achieve long-term survival for LS-PSCCE. ${ }^{9-12}$ However, these retrospective studies had relatively small samples sizes. Due to possible bias in these investigations, the status of radical CRT and surgical treatment in LS-PSCCE is still uncertain. In this study, we sought to further evaluate the efficacy of surgery and CRT for the treatment of LS-PSCCE in a large cohort.

\section{Patients and Methods}

\section{Patients}

A total of 129 patients with pathologically confirmed PSCCE were collected from our hospitals between June 2009 and December 2018. Patients were selected based on the following criteria: (1) limited-stage disease proven through contrast-enhanced computed tomography of the chest and abdomen, bone emission computed tomography scans, and contrast-enhanced computed tomography or magnetic resonance imaging examinations of the brain, (2) Karnofsky performance status (KPS) score $\geq 70$, (3) chemotherapy cycles $\geq 4$, and (4) RT dose $\geq 45 \mathrm{~Gy}$. The exclusion criteria were as follows: (1) history of other malignancies and (2) incomplete medical records. As this was a retrospective study, the requirement to obtain informed consent was waived. This retrospective study was approved by the ethics committees of Shandong Cancer Hospital and Shandong Provincial Hospital, and anonymous patient data were analyzed according to the principles of the Helsinki Declaration.

The patients were staged according to the eighth edition of the American Joint Committee on Cancer (AJCC) TNM Classification of Carcinoma of the Esophagus and Esophagogastric Junction ${ }^{13}$ and the Veterans Administration Lung Study Group (VALG) staging. ${ }^{14}$ The VALG staging system includes limited and extensive stage disease. Limited-stage disease is defined as a tumor confined within a localized anatomic region with or without regional lymph node metastasis. ${ }^{5}$

\section{Treatment Modalities}

The treatment status of patients included in the analysis is shown in Table 2. Of the 81 patients who received CRT and were treated with 4 to 6 courses of cisplatin-based CT (combined with etoposide/irinotecan), 34 patients underwent three-dimensional conformal radiotherapy (3D-CRT) and 47 patients received intensity-modulated radiation therapy (IMRT). The total dose ranged from 45 to 60 Gy (median 54 Gy). There were 49 patients that received concurrent CRT (con-CRT) and 32 patients that received sequential CRT (seqCRT). A total of 48 patients underwent transthoracic esophagectomy and received 4 to 6 cycles of adjuvant CT. Among these, 18 patients with positive surgical margins and/or lymph node metastasis received concurrent adjuvant radiotherapy. Seven patients underwent 3D-CRT and eleven patients received IMRT. The total dose ranged from 45 to $60 \mathrm{~Gy}$ (median: 50 Gy).

\section{Follow-Up}

Patients were followed up once every 3 months for the first 2 years, once every 6 months for the third year, and once annually from the fourth year. During the follow-up visits, the patients underwent routine blood examination, assessment of liver and kidney function and tumor markers, and other laboratory tests as well as a chest and abdominal CT. Bone ECT was performed every six months.

\section{Definitions and Statistical Analysis}

The primary endpoint was overall survival (OS), which was defined as the time from diagnosis to the date of death or last follow-up. The secondary endpoint was recurrencefree survival (RFS). RFS was calculated from the date of diagnosis to the date of the first local or distant progression or to the date of death from any cause. Patients were considered censored if they were without events at the end of the study.

All statistical tests were conducted using SPSS Statistics version 22.0 (IBM Corporation, Armonk, NY, USA) and all figures were produced using GraphPad Prism 8.0 (GraphPad Software, USA). Statistical significance was set at $\mathrm{p}<0.05$. A $\chi^{2}$ test or Fisher's exact test was performed to compare patient baseline characteristics. OS and RFS rates were analyzed using the Kaplan-Meier method. ${ }^{15}$ Univariate and multivariate analyses were performed using a Cox regression model. Variables with a $p$ value of $<0.2$ from univariate analysis were tested in multivariate analysis.

\section{Results}

\section{Patient Characteristics}

The characteristics of the tumors and the 129 patients are summarized in Table 1. The study consisted of a total of 
Table I Cohort Characteristics of I29 Patients with LS-PSCCE

\begin{tabular}{|c|c|c|c|}
\hline \multirow[t]{2}{*}{ Characteristics } & $\begin{array}{l}\text { CRT } \\
\text { Group }\end{array}$ & $\begin{array}{l}\text { Surgery } \\
\text { Group }\end{array}$ & \multirow[t]{2}{*}{$P$ value } \\
\hline & $(n, \%)$ & $(n, \%)$ & \\
\hline Sex & & & 0.131 \\
\hline Female & 25 & 9 & \\
\hline Male & 56 & 39 & \\
\hline Age, y & & & 0.225 \\
\hline$\leq 60$ & 30 & 23 & \\
\hline$>60$ & 51 & 25 & \\
\hline Tobacco abuse & & & 0.271 \\
\hline Yes & 45 & 31 & \\
\hline No & 36 & 17 & \\
\hline Alcohol abuse & & & 0.657 \\
\hline Yes & 44 & 28 & \\
\hline No & 37 & 20 & \\
\hline $\begin{array}{l}\text { Family history of } \\
\text { malignancy }\end{array}$ & & & 0.983 \\
\hline Yes & 17 & 10 & \\
\hline No & 64 & 38 & \\
\hline Location & & & 0.086 \\
\hline Upper & 16 & 3 & \\
\hline Middle & 42 & 32 & \\
\hline Lower & 23 & 13 & \\
\hline Length, cm & & & 0.210 \\
\hline$\leq 4$ & 38 & 28 & \\
\hline$>4$ & 43 & 20 & \\
\hline Macroscopic tumor & & & 0.237 \\
\hline Medullary & 46 & 27 & \\
\hline Ulcerative & 8 & 10 & \\
\hline Mushroom & 16 & 8 & \\
\hline Constrictive & 11 & 3 & \\
\hline TNM stage & & & 0.669 \\
\hline I-II & 34 & 22 & \\
\hline III & 47 & 26 & \\
\hline T stage & & & 0.061 \\
\hline TI-2 & 27 & 24 & \\
\hline T3-4 & 54 & 24 & \\
\hline $\mathrm{N}$ stage & & & 0.075 \\
\hline No & 23 & 21 & \\
\hline $\mathrm{N}+$ & 58 & 27 & \\
\hline
\end{tabular}

80 patients $(62.0 \%)$ from Shandong Cancer hospital and 49 patients (38.0\%) from Shandong Provincial hospital. The study group consisted of 95 men (73.6\%) and 34 women $(26.4 \%)$, and their age ranged from 43 to 78 years (median: 63 years). There were 72 patients $(55.8 \%)$ with a history of alcohol abuse and 27 patients (20.9\%) had a family history of malignancy. The middle third of the thoracic esophagus was the most common location of primary tumors $(57.4 \%)$. The length of these lesions ranged from 1.0 to $9.0 \mathrm{~cm}$ (median: $4.0 \mathrm{~cm}$ ). There was no significant difference in clinical characteristics between the surgery and CRT groups.

\section{OS and RFS for Total Population}

The median follow-up time was 23 months (range: 4-78 months). By June 2019, 11 patients (8.5\%) were still living, 112 patients $(86.8 \%)$ had died, and 6 patients (4.7\%) were lost to follow-up. The median OS of the 129 patients was 25.0 months $(95 \%$ confidence interval [CI]: 22.8-27.2), and the 1-, 3-, and 5-year OS rates were $89.6 \%, 24.0 \%$, and $4.8 \%$, respectively (Figure 1A). The median RFS of all patients was 15.0 months $(95 \% \mathrm{CI}$ : 12.1-17.9) and the 1-, 2-, and 3-year RFS rates were $62.7 \%, 22.0 \%$, and $8.1 \%$, respectively (Figure $1 \mathrm{~B}$ ).

\section{Prognostic Factor Analysis}

We evaluated the relationship between patient prognosis and clinicopathological features (Table 2). In the univariate analysis, patients with a history of alcohol abuse had a shorter median OS than those without a history of alcohol consumption (23.0 versus 27.0 months; $p=0.028)$ (Figure 2A). Patients with tumors $\leq 4 \mathrm{~cm}$ had a better median OS compared with patients with lesion lengths $>4 \mathrm{~cm}$ (29.0 versus 22.0 months; $p<0.001$ ) (Figure $2 \mathrm{~B}$ ). The median OS was increased among patients with stage I-II PSCCE compared with that of patients with stage III PSCCE (32.0 versus 21.0 months; $p<0.001)$. Furthermore, patients with T1-2 PSCCE had a better median OS than those with T3-4 PSCCE (33.0 versus 23.0 months; $p<0.001$ ) (Figure 2C). The median OS of patients with N0 PSCCE was longer than that of patients with N1 and N2 PSCCE (30.0 versus 22.0 versus 18.0 months, respectively; $p<0.001$ ) (Figure 2D). Other clinicopathological features did not show significant correlations with prognosis $(p>0.05)$. According to the multivariate analysis, alcohol abuse and TNM stage were independent prognostic factors (Table 3).

\section{Treatment and Survival}

We compared the survival between patients undergoing CRT and those undergoing surgery. For patients who underwent surgery, the median OS was 26.0 months (95\% CI: 19.9-32.1), 
Table 2 Univariate Analysis for the Prognosis of 129 Patients

\begin{tabular}{|c|c|c|c|c|c|c|}
\hline \multirow[t]{2}{*}{ Variables } & \multirow[t]{2}{*}{ No. of Patients } & \multicolumn{3}{|c|}{ Survival Rate, \% } & \multirow[t]{2}{*}{ MST, mo (95\% Cl) } & \multirow[t]{2}{*}{$p$ value } \\
\hline & & $\mathbf{I - y}$ & 3-y & $5-\mathbf{y}$ & & \\
\hline Sex & & & & & & 0.368 \\
\hline Male & 95 & 87.1 & 20.1 & 5.0 & $24(21.314-26.686)$ & \\
\hline Female & 34 & 96.8 & 35.0 & 3.9 & $27(21.820-32.180)$ & \\
\hline Age & & & & & & 0.439 \\
\hline$\leq 60$ & 53 & 94.2 & 18.4 & 2.3 & $24(21.852-26.148)$ & \\
\hline$>60$ & 76 & 86.4 & 27.8 & 6.5 & $27(22.588-31.4 \mid 2)$ & \\
\hline Alcohol abuse & & & & & & 0.028 \\
\hline Yes & 72 & 83.1 & 16.5 & 3.3 & $23(20.780-25.222)$ & \\
\hline No & 57 & 98.1 & 33.9 & 6.8 & $27(24.785-29.215)$ & \\
\hline Smoking & & & & & & 0.091 \\
\hline Yes & 76 & 86.5 & 16.3 & 3.3 & $24(2|.4| 8-26.582)$ & \\
\hline no & 53 & 94.0 & 34.4 & 6.9 & $27(22.584-31.416)$ & \\
\hline Family history of malignancy & & & & & & 0.988 \\
\hline Yes & 27 & 92.6 & 23.3 & 4.7 & $25(20.565-29.435)$ & \\
\hline No & 102 & 90.8 & 22.9 & 4.8 & $26(23.598-28.402)$ & \\
\hline Location & & & & & & 0.311 \\
\hline Upper & 19 & 94.4 & 32.8 & 6.6 & $27(19.611-34.389)$ & \\
\hline Middle & 74 & 86.3 & 26.4 & 6.2 & $24(19.338-28.662)$ & \\
\hline Lower & 36 & 93.9 & 13.8 & 0.0 & $24(22.28 I-25.719)$ & \\
\hline Length, cm & & & & & & $<0.001$ \\
\hline$\leq 4$ & 66 & 93.7 & 38.9 & 7.4 & $29(24.862-33.138)$ & \\
\hline$>4$ & 63 & 85.3 & 7.8 & 1.9 & $22(19.073-24.927)$ & \\
\hline Macroscopic tumor type & & & & & & 0.109 \\
\hline Medullary & 73 & 87.4 & 21.7 & 5.0 & $24(21.094-26.906)$ & \\
\hline Ulcerative & 18 & 87.8 & 26.2 & 8.7 & $31(17.893-44.107)$ & \\
\hline Mushroom & 24 & 95.5 & 41.8 & 5.2 & $29(25.684-32.316)$ & \\
\hline Constrictive & 14 & 92.9 & 7.1 & 0.0 & $20(17.555-22.445)$ & \\
\hline Treatment modality & & & & & & 0.746 \\
\hline No surgery & 81 & 91.2 & 22.2 & 6.4 & $25(21.993-28.007)$ & \\
\hline Surgery & 48 & 86.8 & 27.0 & 2.5 & $26(19.864-32.136)$ & \\
\hline TNM stage & & & & & & $<0.001$ \\
\hline I-II & 56 & 98.1 & 44.2 & 11.0 & $32(28.639-35.361)$ & \\
\hline III & 73 & 83.3 & 8.6 & 0.0 & $21(19.195-22.705)$ & \\
\hline T stage & & & & & & $<0.001$ \\
\hline TI-2 & 51 & 95.9 & 48.6 & 12.1 & $33(26.744-39.256)$ & \\
\hline T3-4 & 78 & 85.5 & 7.7 & 0.0 & $23(20.857-25.143)$ & \\
\hline$N$ stage & & & & & & $<0.001$ \\
\hline No & 44 & 86.9 & 33.9 & 8.5 & $30(26.154-33.846)$ & \\
\hline NI & 60 & 84.5 & 46.8 & 0.0 & 24(20.529-27.47I) & \\
\hline N2 & 25 & 76.0 & 4.6 & 0.0 & $\mid 8(|4.729-2| .27 \mid)$ & \\
\hline
\end{tabular}

Abbreviations: MST, median survival time; $\mathrm{Cl}$, confidence interval.

and the 1-, 3-, and 5-year OS rates were $86.8 \%, 27.0 \%$, and $2.5 \%$, respectively (Figure $3 \mathrm{~A}$ ). For patients who received
CRT, the median OS was 25.0 months (95\% CI: 22.0-28.0), and the 1-, 3-, and 5-year OS rates were $91.2 \%, 22.2 \%$, and 
A

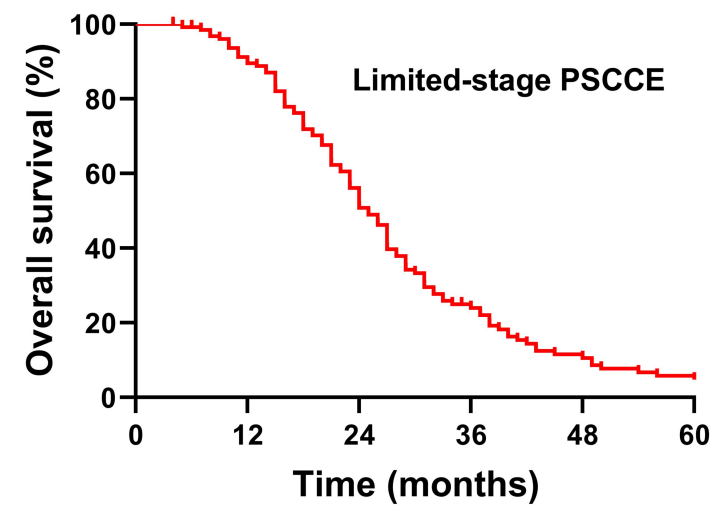

B 웅

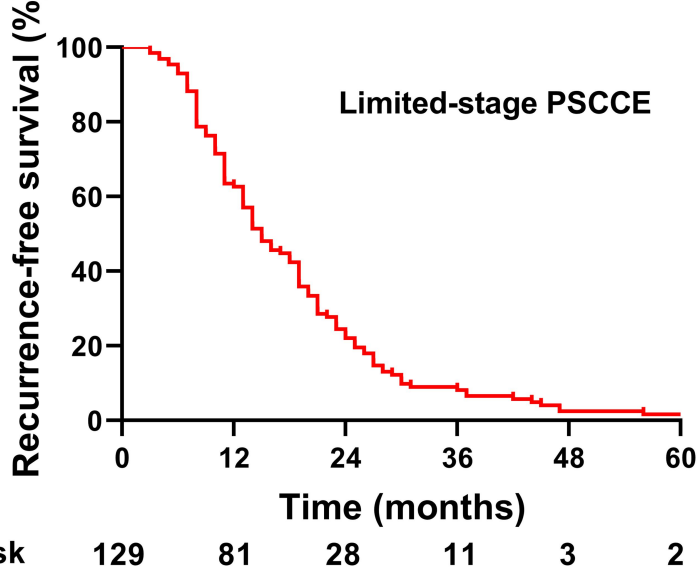

\section{$\begin{array}{llllllllllllll}\text { No. at risk } & 129 & 115 & 65 & 31 & 14 & 6 & \text { No. at risk } & 129 & 81 & 28 & 11 & 3 & 2\end{array}$}

Figure I Survival for all patients. (A) Kaplan-Meier curve of OS for 129 patients with limited-stage PSCCE. (B) Kaplan-Meier curve of RFS for I29 patients with limitedstage PSCCE.

A

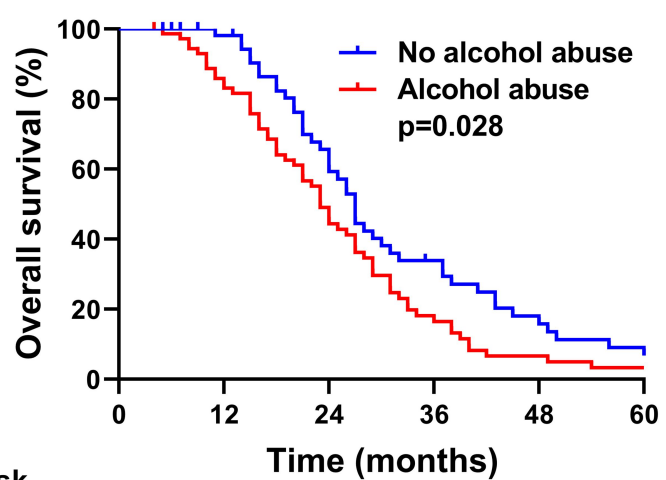

No. at risk

No alcohol abuse $57 \quad 56 \quad 34 \quad 19 \quad 9 \quad 4$

Alcohol abuse $72 \quad 60$

C

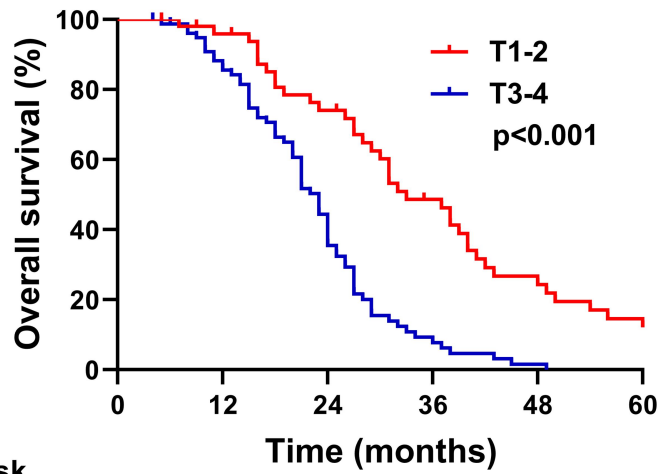

No. at risk

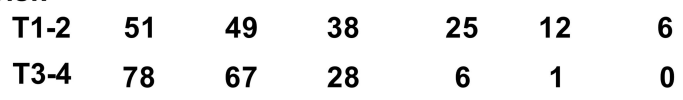

B

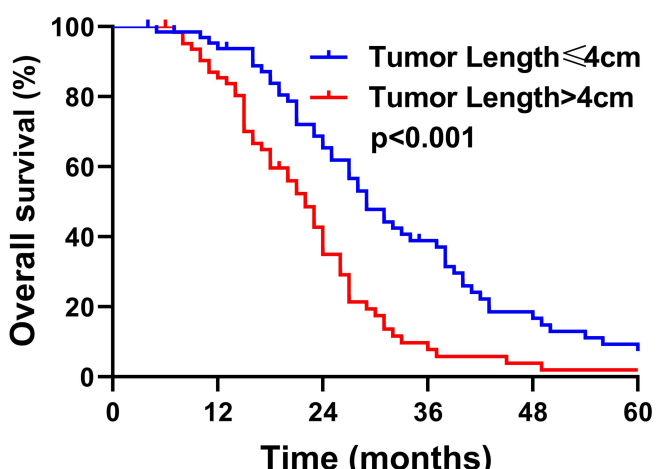

No. at risk

Time (months)

Tumor Length $>4 \mathrm{~cm} 63 \quad 56 \quad 23 \quad 5 \quad 3 \quad 1$

No. at risk

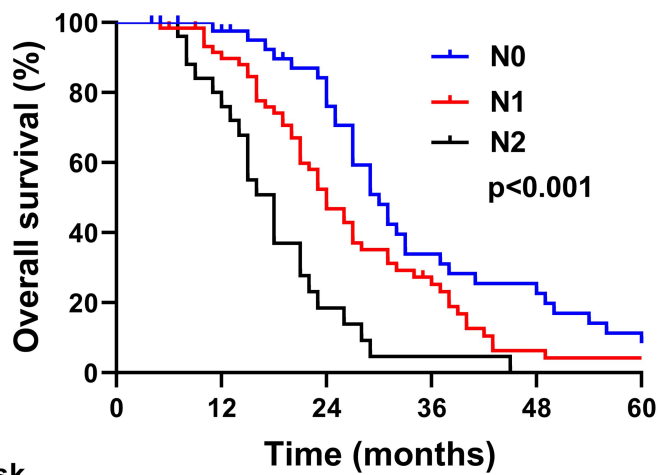

$\begin{array}{ccccccc}\text { N0 } & 44 & 43 & 33 & 18 & 10 & 4 \\ \text { N1 } & 60 & 54 & 28 & 15 & 4 & 3 \\ \text { N2 } & 25 & 19 & 5 & 1 & 0 & 0\end{array}$

Figure 2 Kaplan-Meier survival curves. (A) OS of patients with alcohol abuse. (B) OS of patients with tumor length $\geq 4 \mathrm{~cm}$ or $<4 \mathrm{~cm}$. (C) OS of 129 patients according to T stage. (D) OS of 129 patients according to $\mathrm{N}$ stage.

$6.4 \%$, respectively. The median RFS of the surgery group was

14 months and the median RFS of the CRT group was 19 months ( $p=0.084$ ) (Figure 3B). Of the 56 patients in the stage I-II PSCCE subset, those who underwent CRT exhibited 
Table 3 Multivariate Cox Analysis for the Prognosis of 129 Patients with LS-PSCCE

\begin{tabular}{|l|l|l|}
\hline Variables & $\boldsymbol{p}$ value & RR (95\% CI) \\
\hline Alcohol abuse & 0.046 & $\mathrm{I} .479(\mathrm{I} .007-2.173)$ \\
Smoking & 0.503 & - \\
Length, cm & 0.188 & - \\
Macroscopic tumor type & 0.966 & - \\
TNM stage & $<0.00 \mathrm{I}$ & $3.555(2.36-5.48 \mathrm{I})$ \\
T stage & 0.055 & - \\
N stage & 0.687 & - \\
\hline
\end{tabular}

Abbreviations: $\mathrm{RR}$, relative risk; $\mathrm{Cl}$, confidence interval.

a median OS of 31.0 months, while those who underwent surgery had a median OS of 33 months $(p=0.988)$ The median RFS was 23 months for patients who underwent CRT and 21 months for patients who underwent surgery $(p=0.976)$ (Figure 3C and D). Of the 73 patients in the stage III PSCCE subset, those who underwent CRT exhibited a median OS of 21.0 months compared to a median OS of 20 months in those who underwent surgery ( $p=0.689)$. The median RFS for CRT and surgery was 13 and 10.5 months, respectively $(p=0.990)$ (Figure 3E and F).

We further compared the survival of patients who received con-CRT with those who received seq-CRT. The patients who received con-CRT exhibited a median OS of 27 months (95\% CI: 24.0-29.1), and the 1-, 3-, and 5-year OS rates were $93.8 \%, 29.9 \%$, and $9.2 \%$, respectively. For patients who received seq-CRT, the median OS was 21.0 months (95\% CI: 17.2-24.8), and the 1-, 3-, and 5-year OS rates were $87.1 \%, 9.4 \%$, and $0 \%$, respectively. Patients who underwent con-CRT exhibited better survival than those who underwent seq-CRT ( $p=0.006$, Figure 4A). For those patients who received con-CRT, the RFS was 19.0 months (95\% CI: 14.6-23.4), and the 1-, 2-, and 3 -year RFS rates were $73.1 \%, 34.5 \%$, and $8.6 \%$, respectively. For those patients who received seq-CRT, the RFS was 13.0 months (95\% CI: 9.7-16.3), and the 1-, 2-, and 3 -year RFS rates were $53.1 \%, 12.5 \%$, and $0 \%$, respectively ( $p=0.013$, Figure $4 \mathrm{~B}$ ). The OS and RFS rates of patients who underwent con-CRT were better than those of patients who underwent seq-CRT.

We further compared the OS and RFS of patients who received con-CRT or seq-CRT to those receiving surgery with or without RT. The median OS associated with conCRT, surgery plus CRT, and surgery plus CT was 27, 31, and 24 months, respectively (Figure 5A). There was no significant difference in OS between the three groups. The RFS of patients who received con-CRT or surgery plus
CRT was longer than that of patients who received surgery plus CT (19.0 versus 13.0 months; 21 versus 13.0 months) (Figure 5B). The median OS of seq-CRT, surgery plus CRT, and surgery plus CT was 21, 31, and 24 months, respectively (Figure 5C). The median OS of patients who received surgery plus CRT was better than that of patients in the seq-CRT group ( $p=0.033)$. There was no significant difference in OS between the seq-CRT and the surgery plus CT groups $(p=0.120)$. Patients who received seqCRT had an inferior median RFS compared to patients who received surgery plus CRT or surgery plus CT (13.0 versus 31.0 months; 13.0 vs 24.0 months; $p<0.001$ ) (Figure 5D).

\section{Patterns of Failure}

To date, 46 patients have experienced distant metastasis (DM) in the CRT group. The sites of DM were the liver (15, 32.6\%), an abdominal lymph node (9, 19.6\%), a supraclavicular lymph node $(7,15.2 \%)$, a lung (6, $13.0 \%)$, the brain $(6,13.0 \%)$, bone $(2,4.4 \%)$, and appendix $(1,2.2 \%)$. In the surgery group, 20 patients experienced DM. The sites of DM were the liver $(6,30.0 \%)$, the brain $(5,25.0 \%)$, a supraclavicular lymph nodes (4, $20.0 \%$ ), bone $(3,15.0 \%)$, and an abdominal lymph node (2, $10.0 \%)$.

\section{Discussion}

Due to the low incidence of LS-PSCCE, no prospective studies have been reported thus far, and the optimal treatment strategy for LS-PSCCE remains controversial. Previous studies have recommended surgery combined with CT in patients with LS-PSCCE, ${ }^{5,16}$ and studies have shown that CRT can also achieve good therapeutic effects. $^{10,11}$ Although surgery and RT are the main local treatment options for LS-PSCCE, the method(s) by which the optimal treatment for LS-PSCCE should be selected is still disputed. This retrospective study showed that patients receiving CRT had similar OS and RFS compared to patients receiving surgery and chemotherapy with or without radiotherapy.

It is well known that PSCCE is a systemic disease, and CT is an established choice of treatment. ${ }^{10,16-19}$ For patients with LS-PSCCE, the use of optimal locoregional treatment options varies. Two studies have reported that CRT could be used to avoid surgical complications and delayed postoperative CT in patients with LSPSCCE, ${ }^{10,12}$ but the number of cases in these studies was small (23 and 3 patients). In addition, these studies were 
A

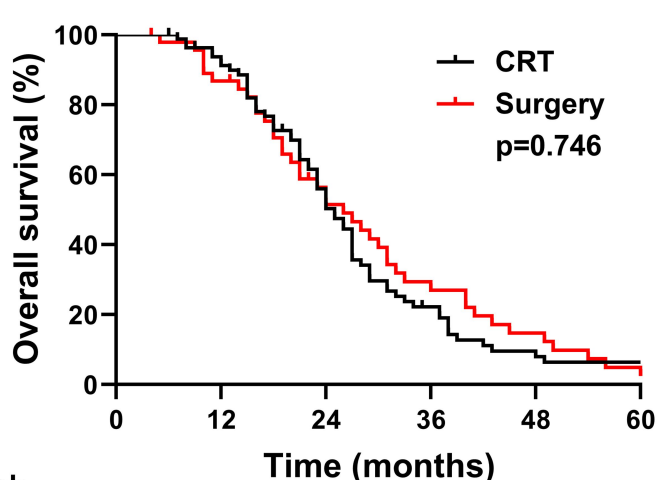

No. at risk

$\begin{array}{lllllll}\text { CRT } & 81 & 74 & 41 & 18 & 6 & 5\end{array}$

$\begin{array}{lllllll}\text { Surgery } & 48 & 42 & 25 & 13 & 7 & 1\end{array}$

C

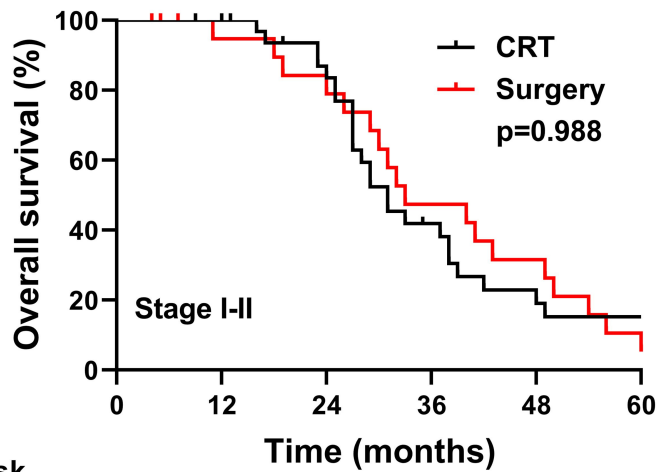

No. at risk

$\begin{array}{lllllll}\text { CRT } & 34 & 34 & 28 & 14 & 6 & 5 \\ \text { Surgery } & 22 & 21 & 17 & 10 & 7 & 1\end{array}$

E

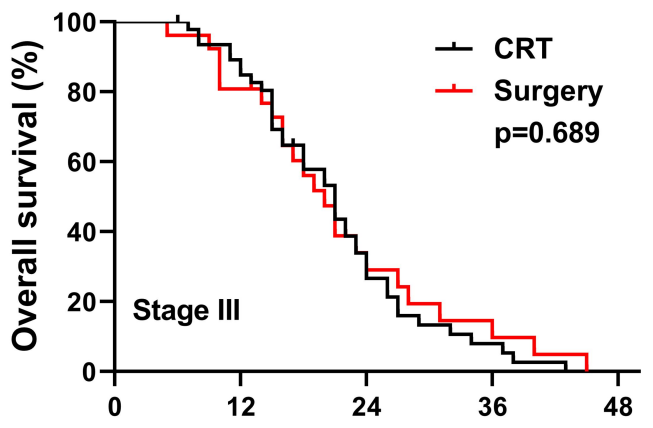

No. at risk

Time (months)

$\begin{array}{cccccc}\text { CRT } & 47 & 40 & 12 & 4 & 0 \\ \text { Surgery } & 26 & 21 & 8 & 3 & 0\end{array}$

B

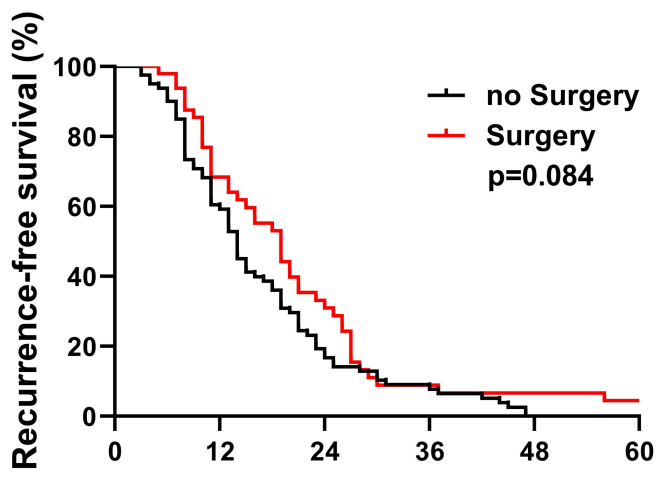

No. at risk

Time (months)

$\begin{array}{ccccccc}\text { CRT } & 81 & 48 & 14 & 6 & 0 & 0 \\ \text { Surgery } & 48 & 33 & 15 & 4 & 3 & 2\end{array}$

D

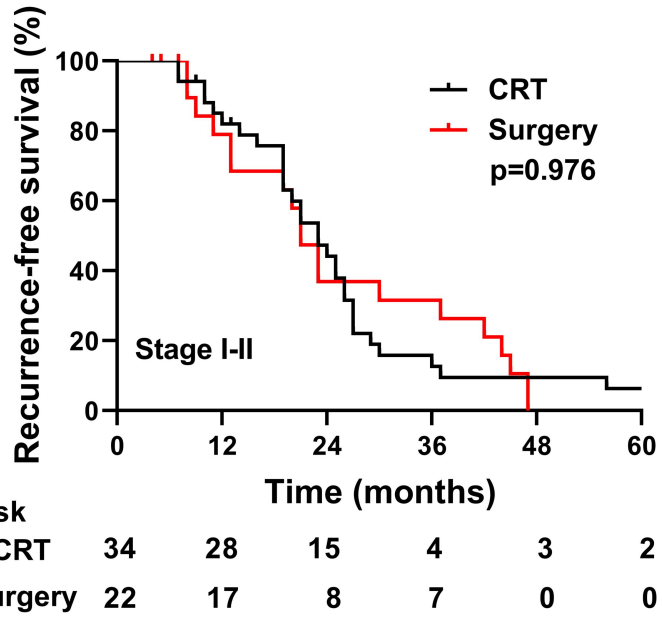

$\mathbf{F}$

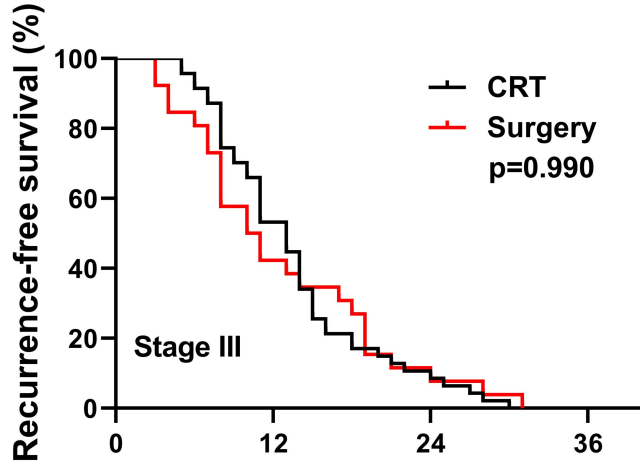

No. at risk

Time (months)

$\begin{array}{ccccc}\text { CRT } & 47 & 25 & 4 & 0 \\ \text { Surgery } & 26 & 11 & 2 & 0\end{array}$

Figure 3 Kaplan-Meier survival curves. (A, B) OS and RFS of patients who received CRT versus patients who received surgery. (C, D) OS and RFS of patients with stage I-II who received CRT versus patients who received surgery. (E, F) OS and RFS of patients with stage III who received CRT versus patients who received surgery.

not able to address whether surgery or radiotherapy was the better option for local therapy. Meng et $\mathrm{al}^{11}$ reported that the CRT group had a better median OS than the surgery plus CT group (33.0 vs 17.5 months, $p=0.019$ ); similar results have been reported in several previous studies. ${ }^{7,20}$ However, several studies have demonstrated that surgery was an effective choice and could be an independent prognostic factor for LS-PSCCE. ${ }^{6,21,22}$ Longterm survival can be achieved in patients with limited disease after surgery. ${ }^{23,24}$ However, it is not yet certain 
A

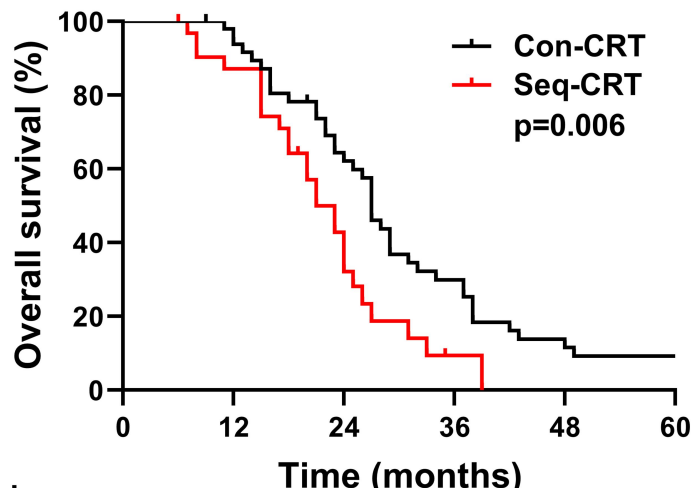

No. at risk

$\begin{array}{rrrrrr}\text { Con-CRT } 49 & 46 & 30 & 15 & 6 & 5 \\ \text { Seq-CRT } 32 & 28 & 10 & 3 & 0 & 0\end{array}$
B

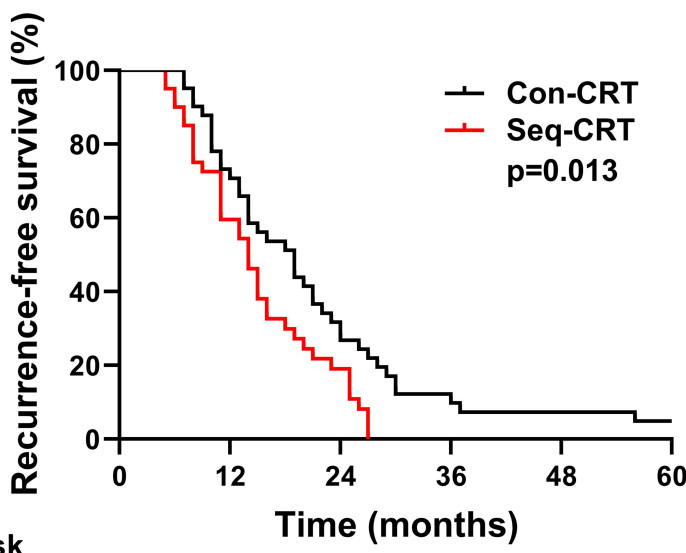

No. at risk

$\begin{array}{rrrrrr}\text { Con-CRT } 49 & 35 & 13 & 5 & 4 & 2 \\ \text { Seq-CRT } 32 & 19 & 6 & 0 & 0 & 0\end{array}$

Figure 4 (A) OS of patients who received concurrent or sequential CRT. (B) RFS of patients who received concurrent or sequential CRT.

A

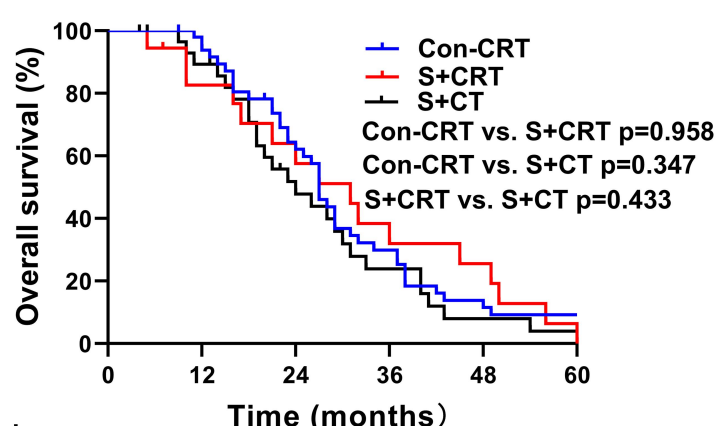

No. at risk

$\begin{array}{rcccccc}\text { Con-CRT } & 49 & 46 & 30 & 15 & 6 & 5 \\ \text { S+CRT } & 18 & 15 & 10 & 6 & 5 & 0 \\ \text { S+CT } & 30 & 27 & 14 & 7 & 2 & 1\end{array}$

C

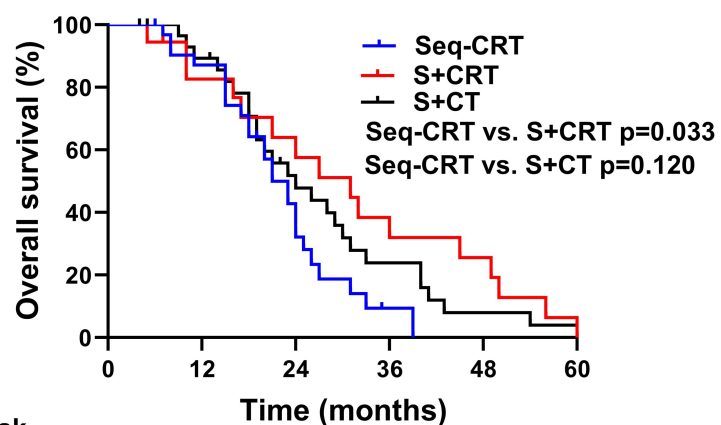

No. at risk

$\begin{array}{rrrrrrr}\text { Seq-CRT } & 32 & 28 & 10 & 3 & 0 & 0 \\ \text { S+CRT } & 18 & 15 & 10 & 6 & 5 & 0 \\ \text { S+CT } & 30 & 27 & 14 & 7 & 2 & 1\end{array}$

B
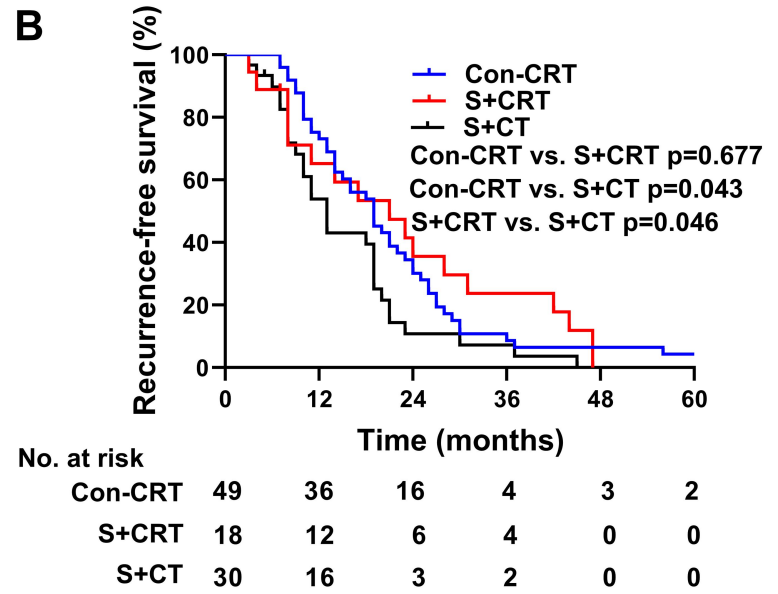

D

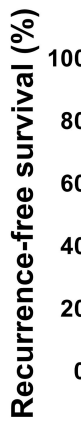

No. at risk

$\begin{array}{rrrrrrr}\text { Seq-CRT } & 32 & 17 & 4 & 0 & 0 & 0 \\ \text { S+CRT } & 18 & 12 & 6 & 4 & 0 & 0 \\ \text { S+CT } & 30 & 16 & 3 & 2 & 0 & 0\end{array}$

Figure 5 Kaplan-Meier survival curves. (A) OS of patients who received con-CRT, surgery plus CRT and surgery plus CT. (B) RFS of patients who received con-CRT, surgery plus CRT and surgery plus CT. (C) OS of patients who received seq-CRT, surgery plus CRT and surgery plus CT. (D) RFS of patients who received seq-CRT, surgery plus CRT and surgery plus CT.

that surgery is better than nonsurgical treatment because these studies included only a small number of patients. In the present study, 84 patients were included to further investigate the application of CRT in LS-PSCCE and we found that the OS and RFS rates of patients who underwent CRT were similar to those of patients who underwent 
surgery plus CT with or without RT. This result is consistent with the findings of previous studies. ${ }^{10,11}$ The median OS of patients in our study was better than was reported in a previous study, which may be due to the fact that more patients received CRT in our study, as well as to improvements in treatment technology. This data supports the view that CRT can be used as one of the treatment options for LS-PSCCE, thereby avoiding the morbidity associated with surgery.

The application of con-CRT in limited-stage small cell lung cancer and esophageal squamous cell cancer has been widely recognized, ${ }^{25-27}$ but its application in PSCCE has not been as thoroughly investigated due to the small number of cases in previous studies. ${ }^{10,11}$ A retrospective study reported that con-CRT could achieve greater OS for LS-PSCCE compared with seq-CRT (36 vs 11 months, $p=0.04$ ) ${ }^{16}$ However, univariate analysis did not detect any difference in survival in a separate study ( 31 vs $22, p=0.37$ ). ${ }^{28}$ This may be due to the fact that nearly half of all patients $(48 \%)$ were diagnosed before 2008 and therefore were treated with relatively outdated technology. As well, a further $18 \%$ of patients demonstrated mixed histology. In the present study, we found that con-CRT achieved longer OS than seq-CRT ( $p=0.006$ ), and that RFS was also longer than that of the seq-CRT group ( $p=0.013$ ). These findings are consistent with the conclusions of Vos et al. ${ }^{16}$ Therefore, con-CRT is recommended to further improve the prognosis of suitable patients.

In the present study, we also found that the con-CRT group had a similar OS to the surgery plus CRT and the surgery plus CT groups, but that con-CRT had better RFS compared to the surgery plus CT group. This indicates that RT can achieve a similar level of control as surgery, and that early RT treatment is beneficial for reducing RFS. However, patients who received seq-CRT had worse OS than those who received surgery plus CRT, and had worse RFS than either surgery plus CRT or surgery plus CT. A previous study demonstrated that con-CRT confers a long-term survival benefit compared with seq-CRT in patients with stage III non-small cell lung cancer. ${ }^{29} \mathrm{Li}$ et $\mathrm{al}^{30}$ confirmed that con-CRT was superior to seq-CRT for the management of esophageal cancer among a Chinese population. Therefore, conCRT may have a better effect on tumor control. Our study is the first to show the survival benefits of conCRT compared with surgery plus CT with or without RT for LS-PSCCE. According to our findings and those of previous studies, con-CRT is recommended as the treatment of choice for LS-PSCCE when the patient's physical status permits, while seq-CRT can be a good choice for patients who are not appropriate for con-CRT. This may require further confirmation by prospective studies.

Previous studies have shown that lesion length, increased radiation dose, and stage, when combined with CT, are better prognostic factors for LS-PSCCE. ${ }^{6,28,31}$ In the present study, univariate analysis revealed that tumor length, alcohol abuse, T stage, $\mathrm{N}$ stage, and TNM stage were associated with prognosis; these results are consistent with those of previous reports. ${ }^{28,31}$ Multivariate analysis showed that alcohol abuse and TNM stage were independent prognostic factors. The correlation between tumor stage and prognosis has been widely recognized, ${ }^{10}$ but the effects of alcohol consumption on prognosis have been less frequently reported, although alcohol consumption has become one of the most common cancer risk factors after smoking. ${ }^{32}$ Lee et $\mathrm{al}^{33}$ recently reported that alcohol abuse is related to worse OS in head and neck cancer. Wang et $\mathrm{a}^{34}$ found that alcohol exposure is associated with invasive breast cancer and promotes the growth and metastasis of mammary tumors. To the best of our knowledge, our study is the first to report that alcohol abuse is related to a worse OS in cases of PSCCE, although the effect of alcohol abuse on the prognosis of PSCCE requires further study.

As a highly malignant and invasive tumor, PSCCE has attracted much attention for its distant metastasis. The researchers of this study were particularly interested in whether patients with PSCCE benefited from prophylactic cranial irradiation (PCI), as is observed in the case of small cell lung cancer. PCI is not routinely recommended, according to the current reports, as the incidence of brain metastases is low $(4.8-12 \%){ }^{19,28,35,36}$ Jeene et al reported that 1 out of 6 patients who underwent PCI developed brain metastases and that of 52 patients without PCI, only 4 developed brain metastases, ${ }^{28}$ thus, no benefit was observed from PCI. As treatment techniques improve, patient survival will increase significantly, and the incidence of brain metastases may increase. For example, the incidence of brain metastases in our study was $16.7 \%$, which is higher than that reported in previous studies. Thus, the role of PCI in PSCCE needs to be further evaluated.

\section{Conclusion}

This study had some limitations. First, this was a retrospective study conducted by two institutions and including nearly a decade of cases; therefore, several 
treatment modalities were involved. The studies analyzed in this paper differed in their diagnosis and treatment of patients. Second, radiotherapy technology has made great progress in recent years; patients treated with RT from today would attain better outcomes than those treated decades ago. Future studies are necessary to define which patients would benefit from advances in radiotherapy technologies.

PSCCE is a systemic disease with rapid progression and a poor prognosis. LS-PSCCE patients treated with CRT had similar OS and RFS compared to those treated with surgery plus CT with or without RT. The present study suggests that radical CRT can be considered as the treatment of choice for LS-PSCCE. The rate of brain metastasis was low, and PCI is not recommended at this moment. This study shows a survival advantage favoring con-CRT compared with seq-CRT for the treatment of LSPSCCE. Thus, con-CRT can be used as the preferred treatment for a better prognosis.

\section{Acknowledgments}

This work was supported by the National Natural Science Foundation of China (grant numbers 81972796 and 81972863), Natural Science Foundation of Shandong Province (grant numbers ZR2019MH010), Yantai Science and Technology Bureau (grant numbers 2020YT06121070) and Binzhou Medical University Research Program and Research Foundation Project (grant number: BY2018KJ30). We would like to thank Editage (www.editage.cn) for English language editing.

\section{Disclosure}

The authors report no conflicts of interest in this work.

\section{References}

1. Chow V, Law S, Lam KY, et al. Telomerase activity in small cell esophageal carcinoma. Dis Esophagus. 2001;14:139-142. doi:10.1046/j.1442-2050.2001.00172.x

2. Hosokawa A, Shimada Y, Matsumura Y, et al. Small cell carcinoma of the esophagus. Analysis of 14 cases and literature review. HepatoGastroenterology. 2005;52:1738-1741.

3. Bennouna J, Bardet E, Deguiral P, et al. Small cell carcinoma of the esophagus: analysis of 10 cases and review of the published data. $\mathrm{Am}$ $J$ Clin Oncol. 2000;23:455-459.

4. Medgyesy CD, Wolff RA, Putnam JB Jr., et al. Small cell carcinoma of the esophagus: the university of texas m. D. Anderson cancer center experience and literature review. Cancer. 2000;88(2):262-267. doi:10.1002/(SICI)1097-0142(20000115)88:2<262::AID-CNCR3>3.0. $\mathrm{CO} ; 2-\mathrm{K}$

5. Xu L, Li Y, Liu X, et al. Treatment strategies and prognostic factors of limited-stage primary small cell carcinoma of the esophagus. $J$ Thorac Oncol. 2017;12:1834-1844. doi:10.1016/j.jtho.2017.09.1966
6. Wong AT, Shao M, Rineer J, et al. Treatment and survival outcomes of small cell carcinoma of the esophagus: an analysis of the national cancer data base. Dis Esophagus. 2017;30:1-5. doi:10.1111/ dote. 12487

7. Brenner B, Tang LH, Klimstra DS, et al. Small-cell carcinomas of the gastrointestinal tract: a review. J Clin Oncol. 2004;22:2730-2739. doi:10.1200/JCO.2004.09.075

8. Cicin I, Karagol H, Uzunoglu S, et al. Extrapulmonary small-cell carcinoma compared with small-cell lung carcinoma: a retrospective single-center study. Cancer. 2007;110:1068-1076. doi:10.1002/ cncr. 22887

9. Ku GY, Minsky BD, Rusch VW, et al. Small-cell carcinoma of the esophagus and gastroesophageal junction: review of the memorial sloan-kettering experience. Ann Oncol. 2008;19:533-537. doi:10.1093/annonc/mdm476

10. Lv J, Liang J, Wang J, et al. Primary small cell carcinoma of the esophagus. J Thorac Oncol. 2008;3(12):1460-1465. doi:10.1097/ JTO.0b013e31818e 1247

11. Meng MB, Zaorsky NG, Jiang C, et al. Radiotherapy and chemotherapy are associated with improved outcomes over surgery and chemotherapy in the management of limited-stage small cell esophageal carcinoma. Radiother Oncol. 2013;106(3):317-322. doi:10.1016/j. radonc.2013.01.008

12. Zhu Y, Qiu B, Liu H, et al. Primary small cell carcinoma of the esophagus: review of 64 cases from a single institution. Dis Esophagus. 2014;27(2):152-158. doi:10.1111/dote.12069

13. Rice TW, Gress DM, Patil DT, et al. Cancer of the esophagus and esophagogastric junction-major changes in the american joint committee on cancer eighth edition cancer staging manual. CA Cancer J Clin. 2017;67:304-317. doi:10.3322/caac.21399

14. Stahel RA. Diagnosis, staging, and prognostic factors of small cell lung cancer. Curr Opin Oncol. 1991;3(2):306-311. doi:10.1097/ 00001622-199104000-00011

15. Lawless J. Statistical Models and Methods for Lifetime Data. New York: Wiley; 1982.

16. Vos B, Rozema T, Miller RC, et al. Small cell carcinoma of the esophagus: a multicentre rare cancer network study. Dis Esophagus. 2011;24:258-264. doi:10.1111/j.1442-2050.2010.01133.x

17. Casas F, Ferrer F, Farrus B, et al. Primary small cell carcinoma of the esophagus: a review of the literature with emphasis on therapy and prognosis. Cancer. 1997;80:1366-1372. doi:10.1002/(SICI)10970142(19971015)80:8<1366::AID-CNCR2 $>3.0 . C O ; 2-D$

18. Maru DM, Khurana H, Rashid A, et al. Retrospective study of clinicopathologic features and prognosis of high-grade neuroendocrine carcinoma of the esophagus. Am $J$ Surg Pathol. 2008;32:1404-1411. doi:10.1097/PAS.0b013e31816bf41f

19. Wang HH, Zaorsky NG, Meng MB, et al. Multimodality therapy is recommended for limited-stage combined small cell esophageal carcinoma. Onco Targets Ther. 2015;8:437-444. doi:10.2147/OTT. S76048

20. Lam KY, Law S, Tung PH, et al. Esophageal small cell carcinomas: clinicopathologic parameters, p53 overexpression, proliferation marker, and their impact on pathogenesis. Arch Pathol Lab Med. 2000;124:228-233. doi:10.1043/0003-9985(2000)124<0228: $\mathrm{ESCC}>2.0 . \mathrm{CO} ; 2$

21. Kukar M, Groman A, Malhotra U, et al. Small cell carcinoma of the esophagus: a seer database analysis. Ann Surg Oncol. 2013;20:4239-4244. doi:10.1245/s10434-013-3167-3

22. Xie MR, Xu SB, Sun XH, et al. Role of surgery in the management and prognosis of limited-stage small cell carcinoma of the esophagus. Dis Esophagus. 2015;28:476-482. doi:10.1111/dote. 12230

23. Nishimaki T, Suzuki T, Nakagawa S, et al. Tumor spread and outcome of treatment in primary esophageal small cell carcinoma. J Surg Oncol. 1997;64:130-134. doi:10.1002/(SICI)1096-9098(199702) 64:2<130::AID-JSO8>3.0.CO;2-C 
24. Mitani M, Kuwabara Y, Shinoda N, et al. Long-term survivors after the resection of limited esophageal small cell carcinoma. Dis Esophagus. 2000;13:259-261. doi:10.1046/j.1442-2050.2000.00124.x

25. Takada M, Fukuoka M, Kawahara M, et al. Phase III study of concurrent versus sequential thoracic radiotherapy in combination with cisplatin and etoposide for limited-stage small-cell lung cancer: results of the japan clinical oncology group study 9104. J Clin Oncol. 2002;20:3054-3060. doi:10.1200/JCO.2002.12.071

26. Fried DB, Morris DE, Poole C, et al. Systematic review evaluating the timing of thoracic radiation therapy in combined modality therapy for limited-stage small-cell lung cancer. $J$ Clin Oncol. 2004;22:4837-4845. doi:10.1200/JCO.2004.01.178

27. Suntharalingam M, Winter K, Ilson D, et al. Effect of the addition of cetuximab to paclitaxel, cisplatin, and radiation therapy for patients with esophageal cancer: the nrg oncology rtog 0436 Phase 3 randomized clinical trial. JAMA Oncol. 2017;3(11):1520-1528. doi:10.1001/jamaoncol.2017.1598

28. Jeene PM, Geijsen ED, Muijs CT, et al. Small cell carcinoma of the esophagus: a nationwide analysis of treatment and outcome at patient level in locoregional disease. Am J Clin Oncol. 2019;42:534-538. doi: $10.1097 /$ COC.0000000000000546

29. Curran WJ Jr., Paulus R, Langer CJ, et al. Sequential vs. Concurrent chemoradiation for stage iii non-small cell lung cancer: randomized phase iii trial rtog 9410. J Natl Cancer Inst. 2011;103:1452-1460. doi:10.1093/jnci/djr325

30. Li F, Li T, Liu L, et al. Concurrent versus sequential chemoradiotherapy for esophageal cancer among chinese population: a meta-analysis. Tumori. 2015;101(4):353-359. doi:10.5301/tj.5000314
31. Chen B, Yang H, Ma H, et al. Radiotherapy for small cell carcinoma of the esophagus: outcomes and prognostic factors from a retrospective study. Rad Oncol. 2019;14:210. doi:10.1186/s13014019-1415-9

32. Kristina SA, Endarti D, Wiedyaningsih C, et al. Estimating the burden of cancer and treatment cost related to alcohol consumption in indonesia: a descriptive study. Asian Pac $j$ Cancer Prev. 2018;19:1845-1849. doi:10.22034/APJCP.2018.19.7.1845

33. Lee WT, Hsiao JR, Ou CY, et al. The influence of prediagnosis alcohol consumption and the polymorphisms of ethanol-metabolizing genes on the survival of head and neck cancer patients. Cancer Epidemiol Biomark Prev. 2019;28:248-257. doi:10.1158/1055-9965.EPI-18-0425

34. Wang Y, Xu M, Ke ZJ, et al. Cellular and molecular mechanisms underlying alcohol-induced aggressiveness of breast cancer. Pharmacol Res. 2017;115:299-308. doi:10.1016/j.phrs.2016.12.005

35. Zou B, Li T, Zhou Q, et al. Adjuvant therapeutic modalities in primary small cell carcinoma of esophagus patients: A retrospective cohort study of multicenter clinical outcomes. Medicine. 2016;95: e3507. doi:10.1097/MD.0000000000003507

36. Xu X, Yang Y, Cao L, et al. Lymph node metastasis and recurrence in primary small cell carcinoma of the esophagus: a retrospective study of 125 cases. Cancer Biother Radiopharm. 2019;34:459-463. doi:10.1089/cbr.2019.2800

\section{Publish your work in this journal}

Cancer Management and Research is an international, peer-reviewed open access journal focusing on cancer research and the optimal use of preventative and integrated treatment interventions to achieve improved outcomes, enhanced survival and quality of life for the cancer patient.
The manuscript management system is completely online and includes a very quick and fair peer-review system, which is all easy to use. Visit http://www.dovepress.com/testimonials.php to read real quotes from published authors. 